\title{
Experimental Study on Friction Sliding Performance of Rubber Bearings in Bridges
}

\author{
Yue Li and Qiqi Wu \\ School of Civil Engineering, North China University of Technology, Beijing 100144, China \\ Correspondence should be addressed to Yue Li; liyue_26@163.com
}

Received 11 March 2017; Accepted 5 April 2017; Published 18 April 2017

Academic Editor: Eric Maire

Copyright (C) 2017 Yue Li and Qiqi Wu. This is an open access article distributed under the Creative Commons Attribution License, which permits unrestricted use, distribution, and reproduction in any medium, provided the original work is properly cited.

\begin{abstract}
To fully ascertain the ultimate shear failure state and the friction sliding performance of laminated rubber bearings in bridges, a series of cyclic loading tests were conducted. The energy dissipation characteristics of the laminated rubber bearings with two end plates, rubber bearings with unilateral friction sliding, and lead rubber bearing (LRB) under low-frequency cyclic loads were compared and analyzed. The results showed the following. (1) The ultimate shear deformation of the rubber bearings with two end plates could reach $300 \%$ to $400 \%$ of the rubber layer thickness. The energy dissipation capacity of the bearings was weak, and the hysteresis curves presented narrow zonal shapes. (2) The rubber bearings with unilateral friction sliding had similar energy dissipation capacities compared to the LRB. With the increase of the sliding distance, the dissipated energy continuously enlarged. The shear deformation of the bearing was no longer increased after reaching the maximum. After the test, the bearings remained in a good condition. The hysteresis curves of the load and displacement presented bilinear shapes. (3) Under the cyclic loading, the energy dissipation capacity of LRB was stable. The hysteresis curves of LRB were always fuller than the laminated rubber bearings.
\end{abstract}

\section{Introduction}

During recent earthquakes in China, the damage of middle and small span girder bridges included mainly girders falling, bearings sliding, collision of the adjacent girders in the expansion joint, and restrainer or abutment damage. Meanwhile, the damage of piers was uncommon [1]. The reason may be that the laminated rubber bearings are widely used in the girder bridges in China. The bearings are put directly on the top of the pier without any effective connection between the piers and girders. In cases of large earthquakes, the relative friction sliding between the bearing and the contact surface of the pier reduces the horizontal seismic load transmitted to the substructure, which plays a role in seismic isolation [1]. This is different from the assumption of bridge seismic design, which requires a load transmission path without interruption; the bearings will not be displaced or damaged, and the seismic energy will be dissipated in the plastic hinge at the bottom of the piers [2].

As an important component connecting the upper and the superstructure in bridges, the bearing has a large influence on the seismic performance of bridges during earthquakes [3]. Iemura et al. [4] studied the effect of steel bearings damage on the seismic dynamic model of bridges and found that, during an earthquake, the mechanical property of the damaged sliding steel bearings is similar to the fixed bearings, which resulted an excessive seismic force being transferred to the bottom of the piers. Kajita et al. [5] discussed the seismic response of elevated continuous girder bridges with damaged bearings. OkazaiI et al. [6] proposed that there were two types of bearing damage models: the first model was supposed to have a fixed connection between the superstructures and piers after the bearing was damaged, and the second model was supposed to have completely separated superstructures and piers after the bearing was damaged. Kim et al. [7] proposed a damage model of bearings based on the change of the friction coefficient and discussed the failure state of movable bearings in earthquakes.

However, the research on the ultimate failure state and the energy dissipation due to the friction sliding of the bearings is insufficient. Stanton and Roeder [8] suggested that the maximum shear deformation of the elastomeric rubber 
TABLE 1: Scheme of the bearing test.

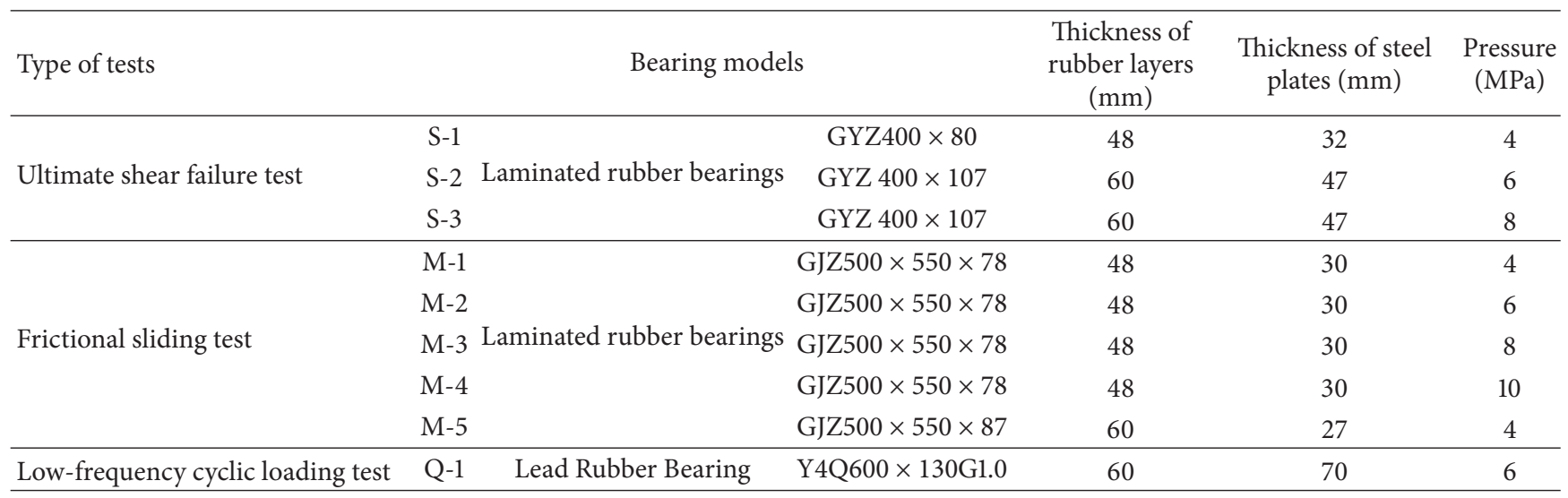

Note: In the ultimate shear failure tests, the GYZ $400 \times 80$ represents that the diameter of the circular rubber bearing is $400 \mathrm{~mm}$ and the total thickness of the bearing is $80 \mathrm{~mm}$. In the frictional sliding tests, the GJZ500 $\times 550 \times 78$ represents that the dimensions of the rectangular bearings are $500 \mathrm{~mm}$ and $550 \mathrm{~mm}$, and the total thickness of the bearing is $78 \mathrm{~mm}$. In the low-frequency cyclic loading test, the Y4Q600 $\times 130 \mathrm{G} 1.0$ represents that there are 4 hole cores in the bearing, the diameter of the LRB is $600 \mathrm{~mm}$ and total thickness is $130 \mathrm{~mm}$. The rest are similar with the above-mentioned.

bearings was $75 \%$ in normal design conditions. Schrage [9] studied the sliding property of the rubber bearing on the concrete surface. Mori et al. [10] found that the ultimate shear deformation of the rubber bearing without being fixed to the two sides could reach $150 \% \sim 225 \%$. Filipov et al. [11] discussed the effect of the sliding friction of the bearing on the seismic performance of bridges. Based on the principle of quasi-isolation, Steelman et al. [12,13] proposed the sliding friction mechanical model of rubber bearings during an earthquake and analyzed the effect of the bearing sliding on the seismic performance of bridges. Buckle et al. [14] studied the stability of rubber bearings under high shear deformation and analyzed the effect of shear deformation on the vertical critical bearing capacity of the bearing. Tang et al. $[15,16]$ proposed the effective control method of the bridge superstructure displacement and discussed the seismic factors affecting the sliding of the rubber bearing. Wang et al. [17, 18] analyzed the effect of the bearing frictional sliding on the seismic response of simple supported girder bridges. Xie and $\mathrm{Wu}$ [19] studied the effect of bearing failure on the seismic response of the restrainer in bridges. Huang et al. [20] proposed the restoring mechanism model considering the failure process of bearings and analyzed the effect of the bearing damage on the seismic response of continuous girder bridges.

To fully ascertain the ultimate shear failure state and frictional sliding performance of laminated rubber bearings, low-frequency cyclic loading tests were conducted. At the same time, the results were compared with the LRB.

\section{Experiment Overview}

Referring to the Series of Elastomeric Pad Bearings for Highway Bridges in China [21], a series of laminated rubber bearing specimens were fabricated and the parameters are listed in Table 1. In the ultimate shear failure test, the two sides of the circular laminated rubber bearings were connected with the loading device. In the friction sliding test (as shown

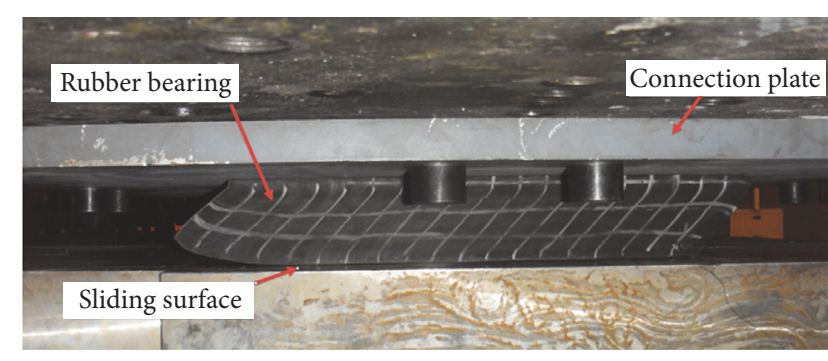

FIGURE 1: Diagram of the friction sliding test.

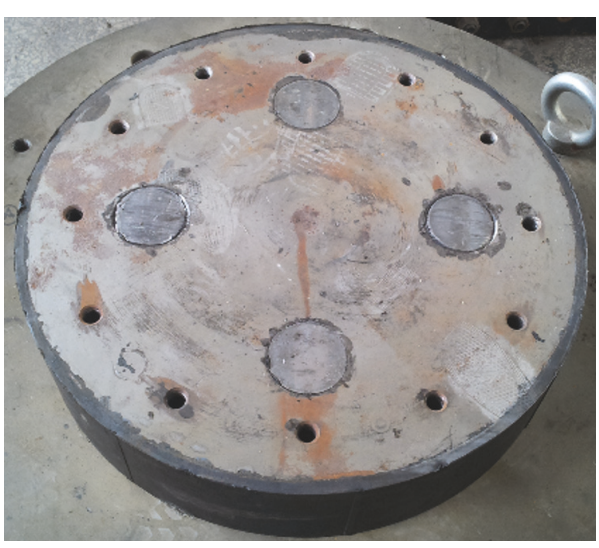

FIGURE 2: The lead rubber bearing in the test.

in Figure 1), only one side of the rectangular laminated rubber bearing was connected with the loading device, while the other side was a layer of rubber cushion which slided on a steel plate support. Figure 2 shows the circular LRB in the test, and the diameter of the 4 hole cores in the LRB is $77 \mathrm{~mm}$.

In the tests, the vertical loading was controlled by the force which applied a certain pressure on the bearings. In the horizontal direction, the loading was controlled by 


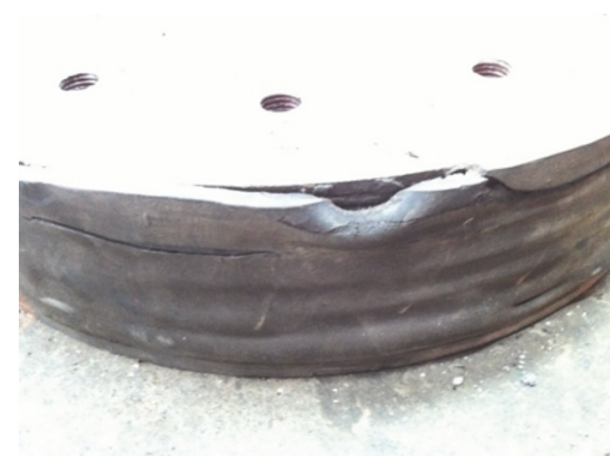

(a) Protective rubber layer separated from the body

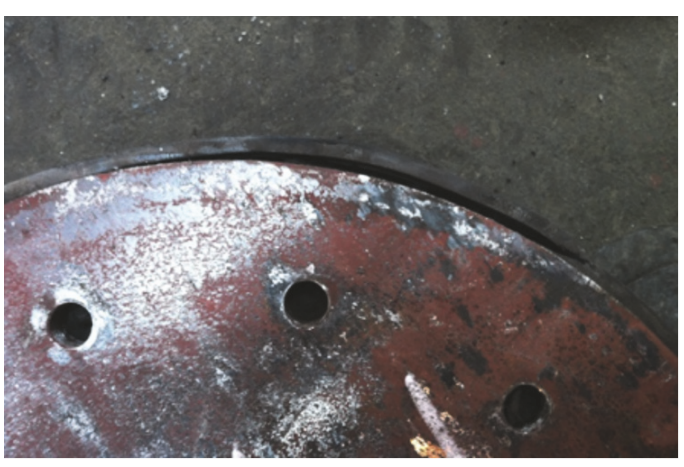

(b) Protective layer rubber striped

FIgURE 3: Partial failure of the bearing when $E=200 \%$.

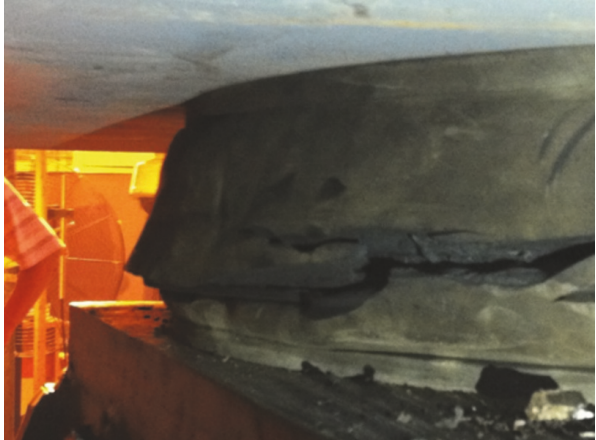

(a) Rubber bearing layer ruptured (S-3)

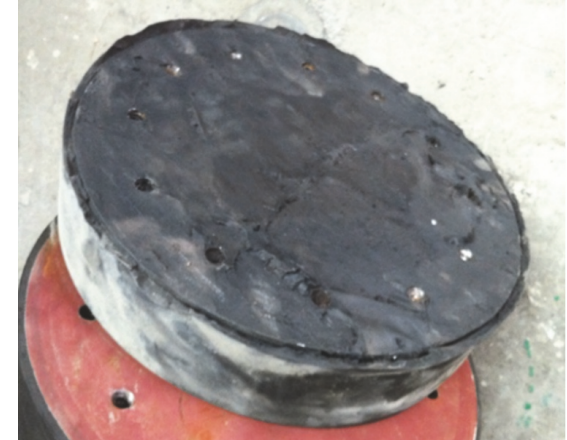

(b) Rupture surface of shear failure (S-3)

FIgURE 4: Shear failure of the bearings after $E \geq 350 \%$.

the displacement. Under the low-frequence cyclic load, the shear deformation amplitude $(E)$ represented the ratio of the displacement to the rubber layer thickness of the bearing. And the amplitudes were 50\%, 100\%, 150\%, 200\%, 250\%, and $300 \%$, respectively.

\section{Experimental Phenomena}

3.1. Ultimate Shear Failure Test of the Elastomeric Rubber Bearings. During the test, with the increase of shear deformation, the bearing was gradually damaged. The damage phenomenon of the rubber bearings was similar. Taking the S-3 as an example, when $E=200 \%$, the local failure was detected on the bearings, such as the protective rubber layer getting separated from the bearing body and expanding outwards (as shown in Figure 3). When $E=$ $300 \%$, internal failure occurred, and the fracture noise of the rubber layer appeared during the test. When $E$ increased beyond $350 \%$ (as shown in Figure 4), the rubber layer was completely broken, and the shear stiffness of the bearing was lost.

Under the low-frequency cyclic loading, the hysteresis curves of the laminated rubber bearing are shown in Figure 5. Due to the residual deformation of the bearing, the hysteresis curve is a narrow zonal shape representing a small amount of energy dissipation. When $E$ remains less than $200 \%$, the

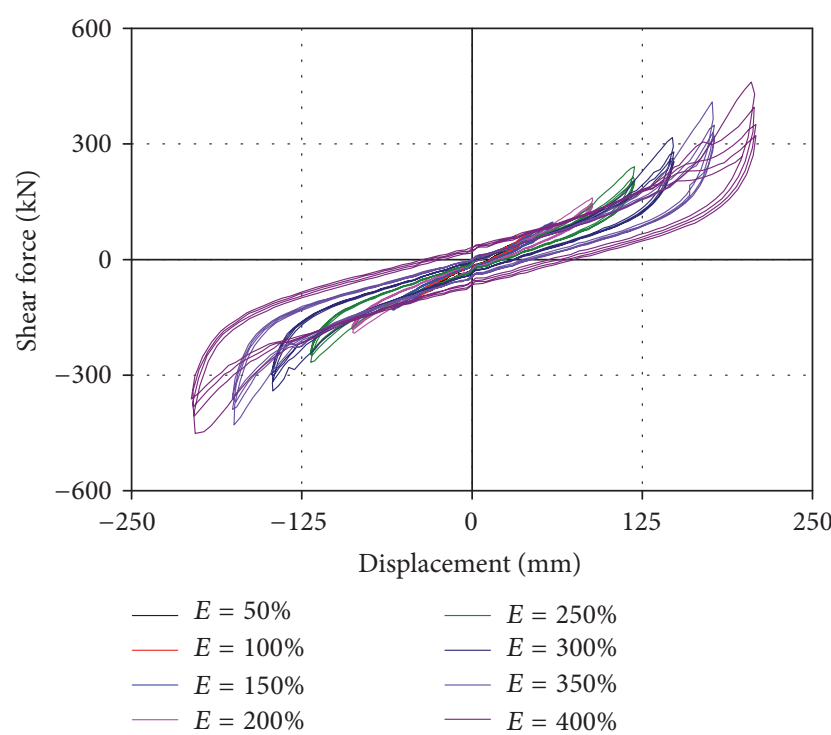

FIgure 5: The hysteresis curves of the laminated rubber bearing (S-3).

bearing is still in the elastic deformation stage. When $E$ goes beyond $300 \%$, the shear stiffness of the bearings will be degenerated, and the hysteresis curve presents a "Z" shape. 


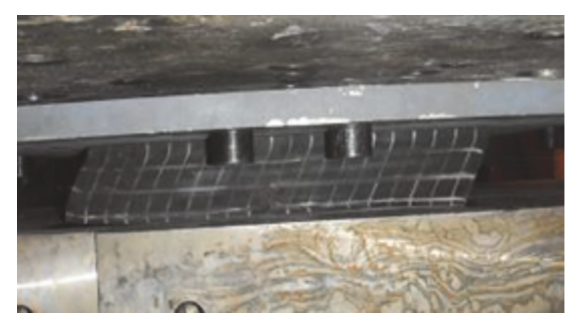

(a) $E=50 \%$

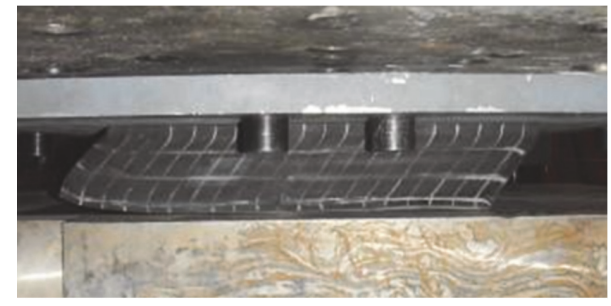

(c) $E=200 \%$

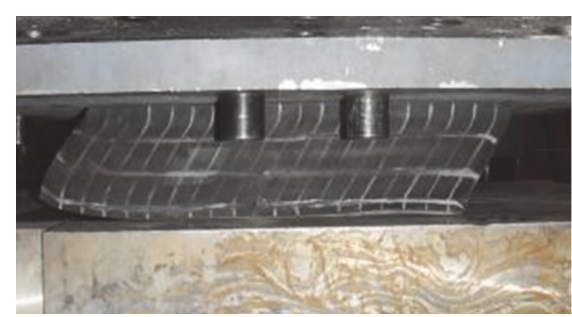

(b) $E=100 \%$

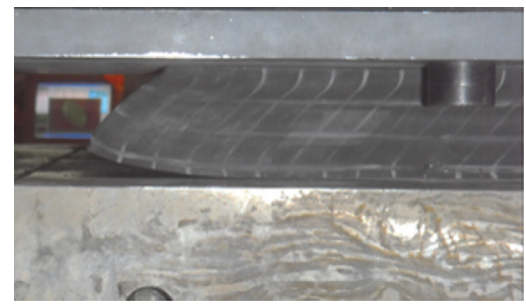

(d) $E=300 \%$

FIgURE 6: Friction sliding phenomenon (M-2).

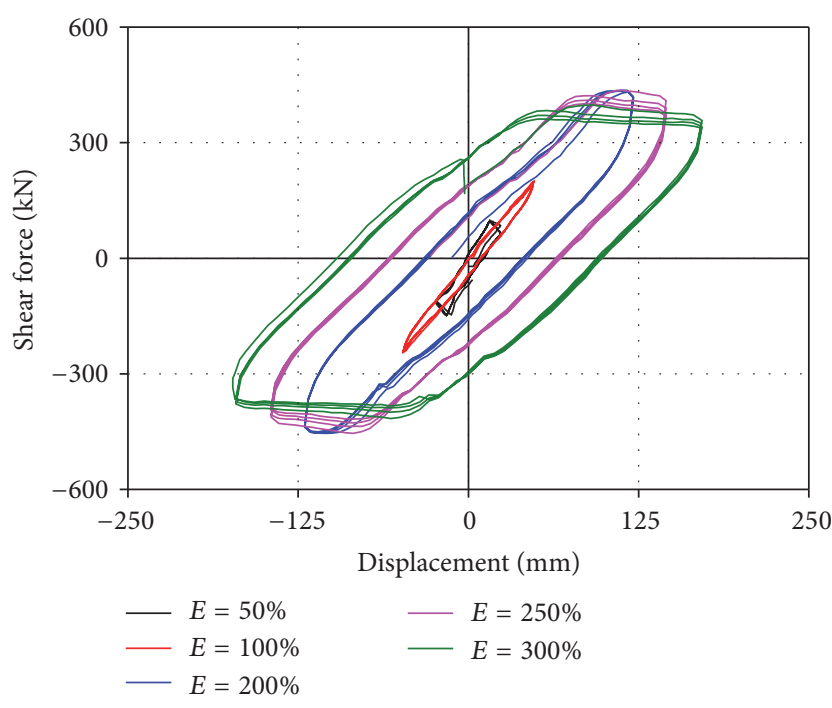

FIGURE 7: The hysteresis curve of the bearing sliding friction (M-2).

Simultaneously, the energy dissipation in a single cycle is gradually increasing.

\subsection{Friction Sliding Test of the Elastomeric Rubber Bearings.} In the friction sliding tests, the damage phenomenon of the rubber bearings is also similar. Taking the M-2 as an example, the typical displacement process during the loading is shown in Figure 6. When $E<100 \%$, accompanied with small frictional sliding, the elastic shear deformation mainly occurred in the bearing (shown in Figure 6(a)). The hysteresis curve presents a linear narrow shape (shown in Figure 7). With the increase of the displacement, the bearing experienced a longer friction sliding distance. Warpage deformation occurred at the corner of the bearings (shown in Figure 6(b)). The hysteresis curve presented bilinear distributions and

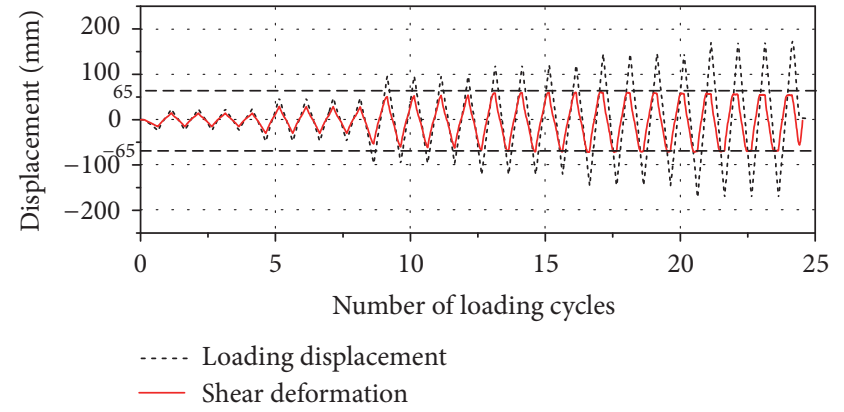

FIGURE 8: History curve of the friction sliding displacement.

was no longer linear. When $E$ reached $200 \%$, the warpage deformation at the corner of the bearing further increased (shown in Figure 6(c)). At the same time, the maximum displacement reached $55 \mathrm{~mm}$, and the maximum shear deformation reached $65 \mathrm{~mm}$ (shown in Figure 8). Thereafter, the maximum shear deformation of the bearing remained constant, while the sliding distance of the bearing increased. After the test, despite the bottom rubber layer being stripped off, the bearing returned to the original status and remained roughly intact without shear failure of the rubber layers.

3.3. Cyclic Load Test of the Lead Rubber Bearings. The energy dissipation of the lead rubber bearing is mainly fulfilled by the deformation of the lead cores. Under a horizontal cyclic load, the stiffness after yielding of the bearing was slightly decreased, and the energy dissipation was increased with the shear deformation. During the test, the energy dissipation capacity of the lead rubber bearing presented good stability. No abnormal appearance was observed, and the hysteresis curves were always full (shown in Figure 9). After the test, the bearing was essentially restored to its original condition. 


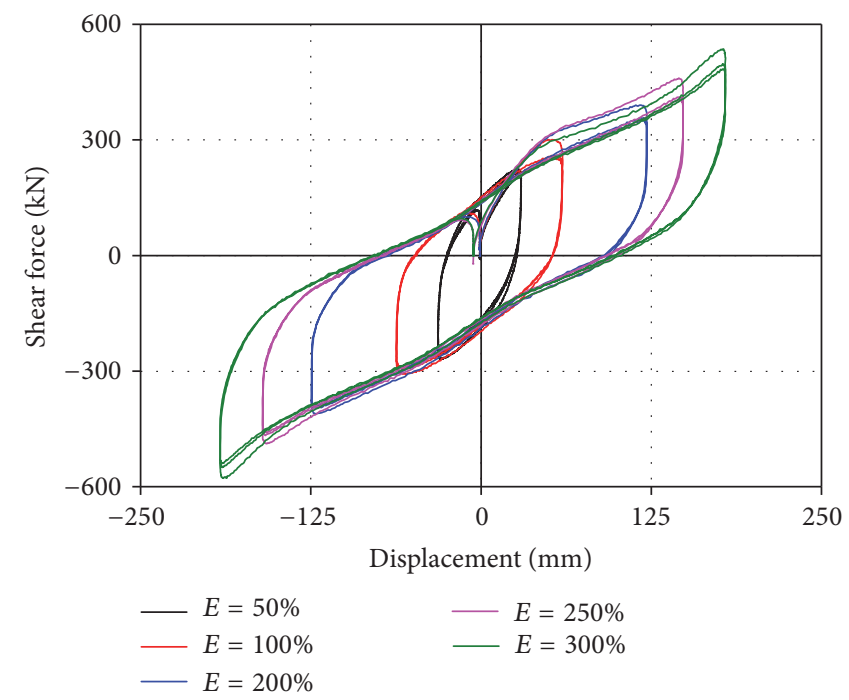

FIGURE 9: The hysteresis curves of the LRB.

\section{Experiment Results Analysis}

4.1. Energy Dissipation Capacity of the Bearings. Under cyclic load, the area surrounded by the hysteresis curve represents the energy dissipation capacity of the bearing. In the ultimate shear failure tests of the elastomeric bearings and the cyclic loading test of the lead rubber bearing, the energy dissipation only depended on the shear deformation. However, in the frictional sliding test, the energy dissipation relied not only on the shearing deformation but also on the friction. Due to the mechanism difference, it is necessary to compare and analyze the three types of energy dissipation forms. S-3, M5 , and Q-1 represent the three target specimens with identical thicknesses of rubber layers. Their energy dissipation capacity was analyzed (as shown in Figure 10).

From Figure 10, it is observed that the hysteresis curve of S-3 always presents a narrow stripe shape in every stage and the energy dissipation capacity was poorer than M-5 and Q-1, while the LRB (Q-1) specimen dissipated energy at the beginning, and the shear deformation occurred. The hysteresis curve of the LRB presents a full spindle shape.

From the relationship curve between the energy dissipation and the shear deformation, it is found that, before $E<$ $200 \%$, both in the ultimate shear failure test and in the friction sliding test, the energy dissipation capacity of the bearings was always less than the LRB (as shown in Figure 11). The reason is mainly that the lead core in the lead rubber bearing began to dissipate energy in little deformation, while the elastomeric rubber bearing was still in its elastic deformation state. The residual deformation and sliding displacement were low, which led to the poor energy dissipation. When $E$ reached $200 \%$, with the increasing of sliding displacement, the dissipated energy was gradually increased due to the friction. The hysteresis curve transformed from a narrow band to a full spindle shape. After $E>200 \%$, the dissipated energy of the rubber bearing by friction was larger than the lead rubber bearing. Compared to the results of M-5 and
Q-1, when $E$ was equal to $50 \%$ and $100 \%$, respectively, the dissipated energy of M-5 was $14 \%$ and $30 \%$ of Q-1 in a single cycle. When $E$ increased to $250 \%$ and $300 \%$, respectively, the dissipated energy of M-5 was $109 \%$ and $126 \%$ of Q- 1 in a single cycle.

It can be found that only the sliding friction made the elastomeric rubber bearing dissipate more energy. With the increase of sliding displacement, the more the energy dissipated, the closer the elastomeric rubber bearing could get to the energy dissipation capacity of the LRB. The energy dissipation capacity of the LRB was increased with the shear deformation and presented an approximately positive proportion.

4.2. Analysis of the Friction Sliding Test. To clarify the effect of the friction sliding on the energy dissipation capacity of the bearings, the results of the four bearings (M-1 M-4) with the same rubber layer thickness were analyzed.

4.2.1. Shear Deformation of the Bearing. From Figure 12, it can be observed that the shear deformation increased with an increase in the vertical load. When the vertical loads were $4 \mathrm{MPa}, 6 \mathrm{MPa}, 8 \mathrm{MPa}$, and $10 \mathrm{MPa}$, the average shear deformation values due to the bearing sliding were $32 \mathrm{~mm}$, $35 \mathrm{~mm}, 44 \mathrm{~mm}$, and $53 \mathrm{~mm}$, respectively, which were $67 \%$, $73 \%, 92 \%$, and $110 \%$ of the total rubber thickness.

4.2.2. Equivalent Stiffness. Under vertical loads, the equivalent stiffnesses $k_{b \text {, eff }}$ are similar to each other, which is calculated by the following equation:

$$
k_{b, \text { eff }}=\frac{F_{y}}{d_{u}}=\frac{\mu_{f} R_{d}}{d_{u}},
$$

where $F_{y}$ is the friction force between the surfaces of the bearing and support, $\mu_{f}$ is the friction coefficient, $R_{d}$ is the 


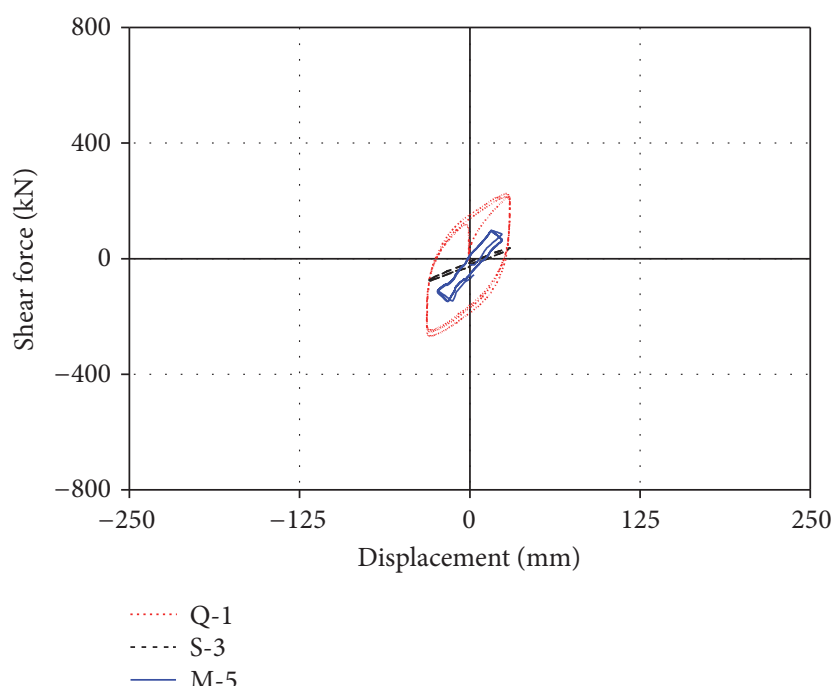

(a) $E=50 \%$

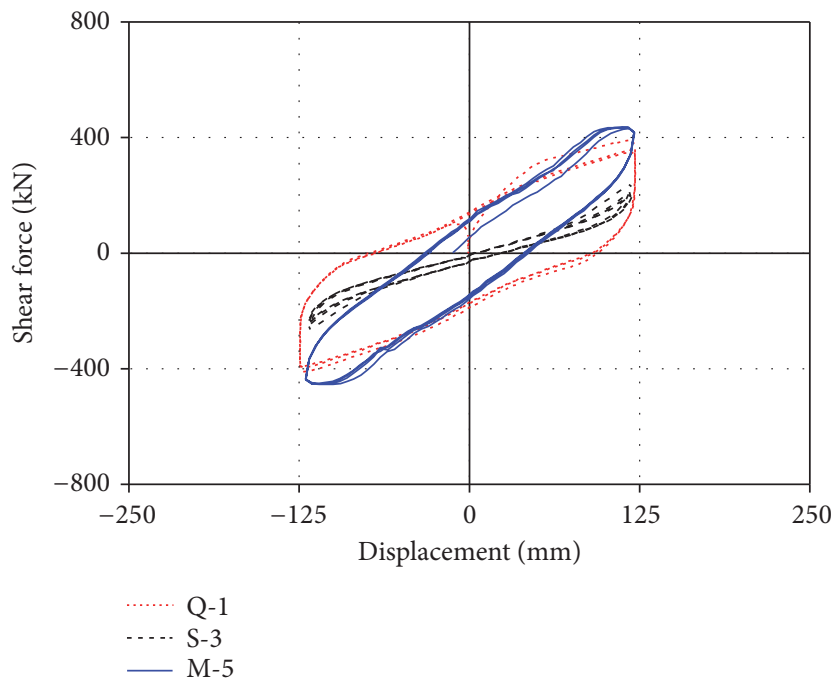

(c) $E=200 \%$

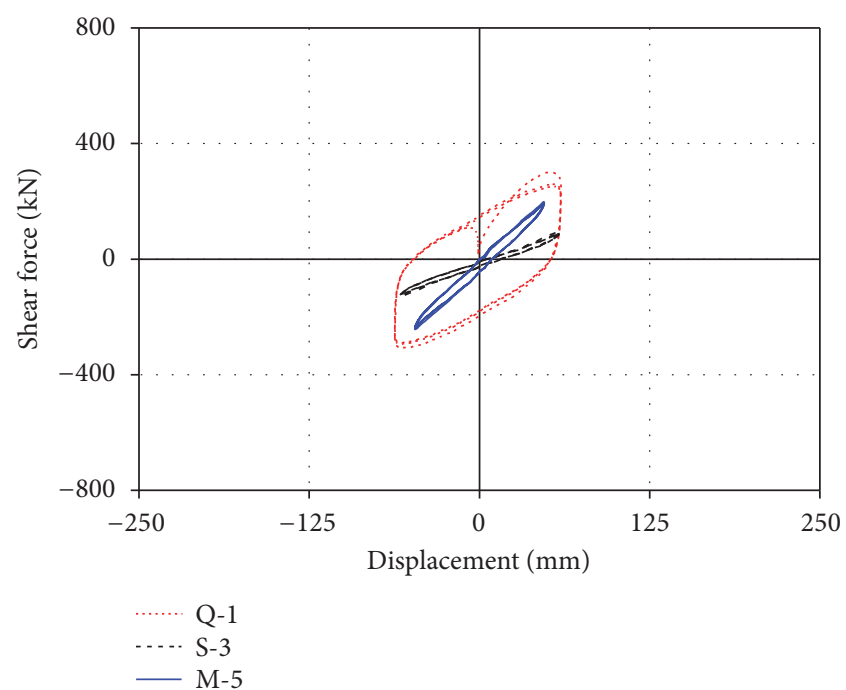

(b) $E=100 \%$

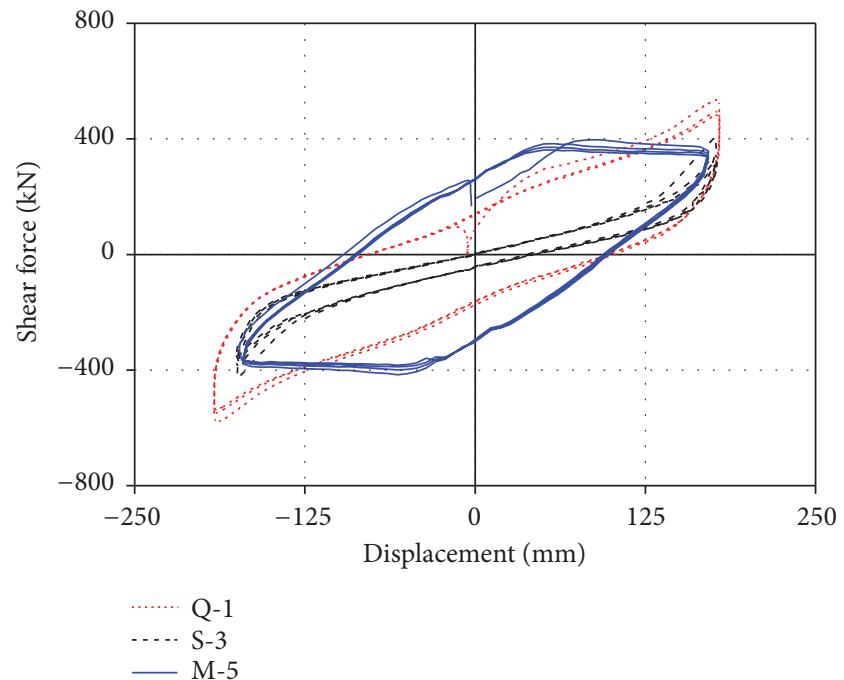

(d) $E=300 \%$

FIGURE 10: The hysteresis curve of the bearings in different stages.

supporting force, and $d_{u}$ is the maximum displacement of the bearing. The variation trend of the equivalent stiffness degradation curve of the rubber bearing is similar and presents a nearly linear shape (shown in Figure 13). The equivalent stiffness decreases with the increase of the shear deformation.

4.2.3. Friction Force and Friction Coefficient. The variation of the friction force under different vertical loads is represented by the load-displacement curve of a single monotonic loading process. With the increase of the vertical load, the friction force was increased (as shown in Figure 14). The bearing stiffness shows an obvious hardening effect. The friction coefficient was inversely proportional to the vertical load. When $P=4 \mathrm{MPa}$, the friction coefficient $\mu=0.30 \sim 0.40$; when $P=6 \mathrm{MPa}, \mu=0.20 \sim 0.30$; when $P=8 \mathrm{MPa}, \mu=$ $0.15 \sim 0.25$ (as shown in Figure 15).

\section{Conclusions}

Considering the laminated rubber bearings of bridges in China, ultimate shear failure and friction sliding tests were conducted. The mechanism of the energy dissipation of the laminated rubber bearings was analyzed and compared with lead rubber bearing. The main conclusions are as follows:

(1) In the ultimate shear failure test, when the shear deformation reached $200 \%$, the protective rubber layer of the laminated rubber bearings began to be separated from the bearing body. When the shear deformation reached $300 \%$ to $400 \%$, the different parts of the bearings failed which led to the complete loss of the shear stiffness and the shear capacity. In the test, the hysteresis curve of the laminated rubber bearings had a narrow zonal shape, which indicated that the energy dissipation capacity was poor. 


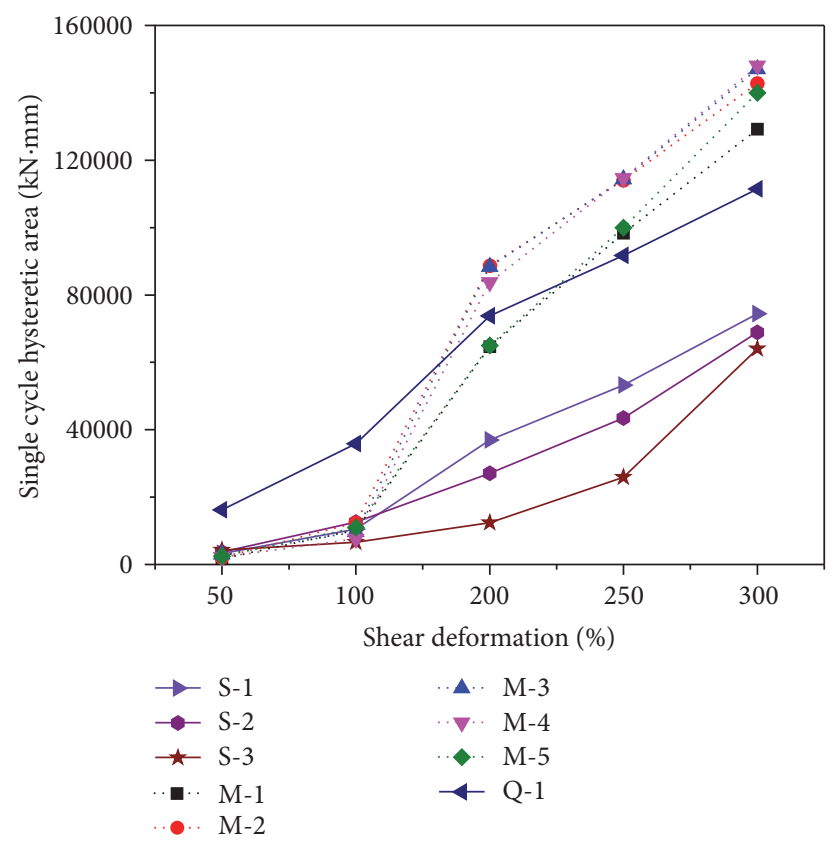

FIGURE 11: Shear deformation and energy dissipation curve.

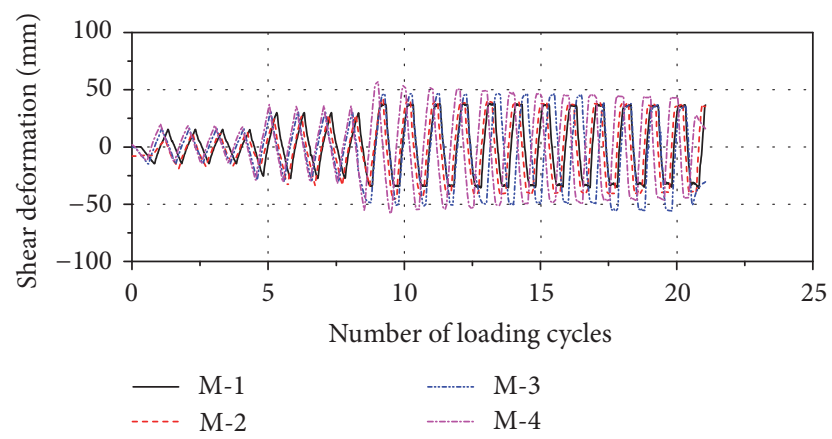

FIGURE 12: History curve of the shear deformation.

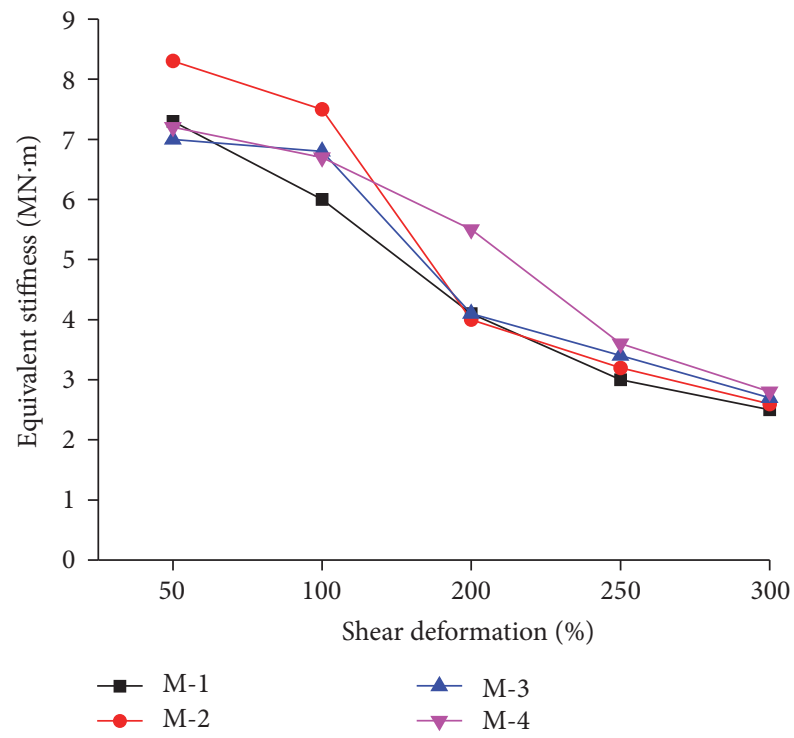

FIGURE 13: Equivalent stiffness of the bearings under vertical load.

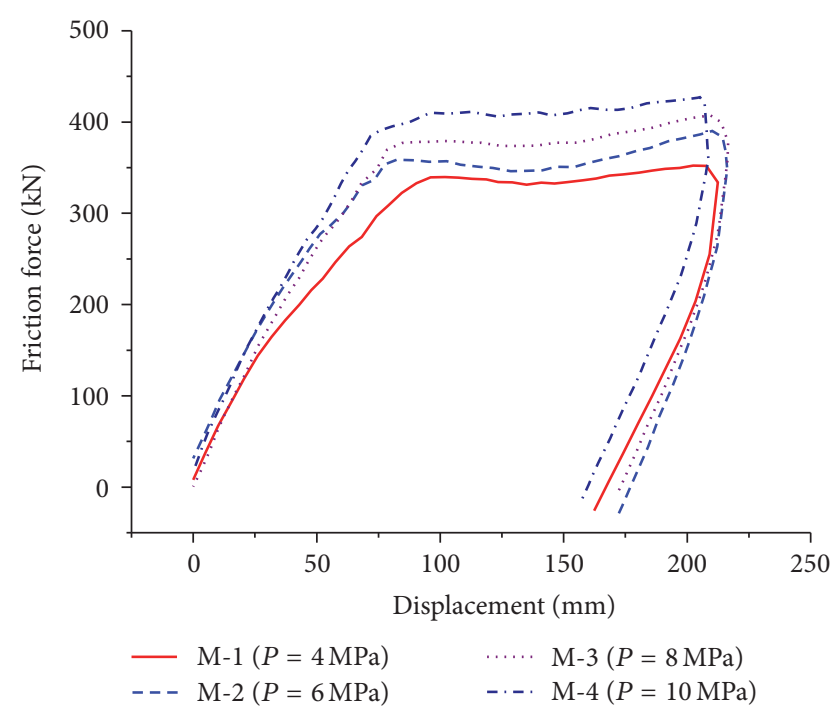

FIGURE 14: Relationship of friction force and displacement.

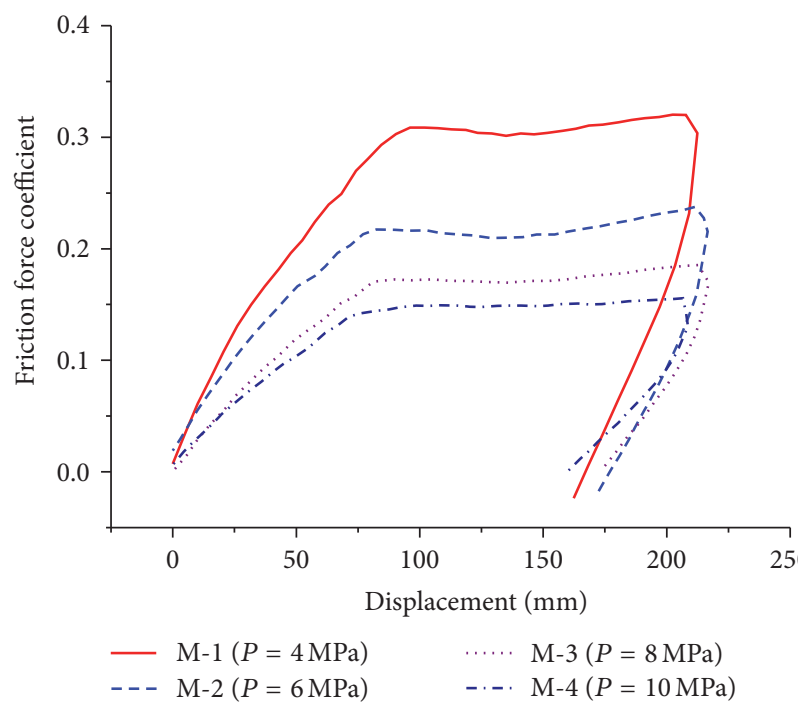

FIGURE 15: Relationship of friction force coefficient and displacement.

(2) In the frictional sliding test, the energy dissipation capacity of the laminated rubber bearings was close to the lead rubber bearing. The maximum energy dissipation in a single cycle could achieve $126 \%$ of the lead rubber bearing. With the increase of the displacement, the amount of dissipated energy was increased, while the shear deformation of the bearing was no longer increased after reaching the maximum. After the test, the bearings remained intact. The hysteresis curves presented a bilinear shape. With the increase of the vertical load, the friction force was increased, while the friction coefficient was decreased.

(3) Under the cyclic loading, the energy dissipation capacity of the LRB was stable. At the beginning of the loading, the LRB began to dissipate energy. During 
the test, the appearance of the LRB remained intact. After the test, the LRB returned to its original condition. The hysteresis curves of the LRB were always full.

(4) Although the frictional sliding of the laminated rubber bearings led to energy dissipation, it is difficult to control the displacement of the superstructure in bridges. It is necessary to effectively control the relative displacement between the superstructure and the piers of bridges by a retaining system.

\section{Conflicts of Interest}

The authors declare that they have no conflicts of interest.

\section{Acknowledgments}

This research work was supported by the National Natural Science Foundation of China (Grants nos. 51408009 and 51608010), China Postdoctoral Science Foundation (Grant no. 2012M530022), and Cultivation Project for Outstanding Young Teachers of North China University of Technology (Grant no. XN072-032).

\section{References}

[1] L. C. Fan and J. Z. Li, "Analysis of seismic damage and antiseismic design measures on bridges in Wenchuan," Highway, vol. 5, pp. 122-128, 2009.

[2] K. Kawashima, "Seismic design and retrofit of bridge," in Proceedings of the 12th World Conference on Earthquake Engineering, pp. 280-291, 2000.

[3] A. Fäcke, M. Baur, and F. H. Schlüter, "Assessment of bridge performance-seismic isolation versus ductility," in Proceedings of the 14th World Conference on Earthquake Engineering, pp. 560-579, 2008.

[4] H. Iemura, A. Miyamoto, and Y. Akahashi, "Influence of failure of steel bearings on damage modes of bridges under strong Earthquake motion," Journal of Structural Engineering, vol. 44A, pp. 659-666, 1998.

[5] Y. Kajita, E. Watanabe, and K. Sugiura, "Seismic response of elevated bridges considering the failure of steel bridges and assessment on effectiveness of fall-off prevention devices," Journal of Structural Engineering, vol. 23, pp. 903-914, 1999.

[6] M. Okazail, H. Tsuda, and M. Dogaki, "Seismic response of continuous bridges supported by seismic isolation bearings in consideration of collision between girders," Journal of Structural Engineering, vol. 48A, pp. 899-907, 2002.

[7] S.-H. Kim, H.-S. Mha, and S.-W. Lee, "Effects of bearing damage upon seismic behaviors of a multi-span girder bridge," Engineering Structures, vol. 28, no. 7, pp. 1071-1080, 2006.

[8] J. F. Stanton and C. W. Roeder, "Elastomeric bearings design, construction, and materials," National Cooperative Highway Research Program 248, Washington, DC, USA, Transportation Research Board, National Research Council, 1982.

[9] I. Schrage, Anchoring of Bearing by Friction (Special Publication SP70-12), American Concrete Institute (ACI), Detroit, Mich, USA, 1981.
[10] A. Mori, P. J. Moss, N. Cooke, and A. J. Carr, "The behavior of bearings used for seismic isolation under shear and axial load," Earthquake Spectra, vol. 15, no. 2, pp. 199-224, 1999.

[11] E. T. Filipov, J. F. Hajjar, J. S. Steelman, L. A. Fahnestock, J. M. Lafave, and D. A. Foutch, "Computational analyses of quasi-isolated bridges with fusing bearing components," in Inproceedings of the Structures Congress 2011, pp. 276-288, April 2011.

[12] J. S. Steelman, L. A. Fahnestock, J. M. Lafave, J. F. Hajjar, E. T. Filipov, and D. A. Foutch, "Seismic response of bearings for quasi-isolated bridges- Testing and component modeling," in Inproceedings of the Structures Congress 2011, pp. 164-178, April 2011.

[13] J. S. Steelman, L. A. Fahnestock, E. T. Filipov, J. M. Lafave, J. F. Hajjar, and D. A. Foutch, "Shear and friction response of nonseismic laminated elastomeric bridge bearings subject to seismic demands," Journal of Bridge Engineering, vol. 18, no. 7, pp. 612-623, 2013.

[14] I. Buckle, S. Nagarajaiah, and K. Ferrell, "Stability of elastomeric isolation bearings: experimental study," Journal of Structural Engineering, vol. 128, no. 1, pp. 3-11, 2002.

[15] H. Tang and J. Z. Li, "Displacement control method for continuous bridges on laminated rubber bearings under earthquake excitation," China Journal of Highway and Transport, vol. 26, pp. 110-116, 2013.

[16] L. C. Fan, L. Y. Nie, and J. Z. Li, "Dynamic characteristic analysis of laminated rubber bearing sliding under earthquake," China Journal of Highway and Transport, vol. 16, pp. 30-35, 2003.

[17] D. S. Wang and Q. M. Feng, "Effects of frictional force at movable supports on earthquake response of simply supported reinforced concrete bridges," Earthquake Engineering and Engineering Vibration, vol. 18, pp. 30-39, 1998.

[18] D. S. Wang, X. Guo, and Z. G. Sun, "Damage to highway bridges during Wenchuan Earthquake," Journal of Earthquake and Engineering Vibration, vol. 29, pp. 84-94, 2009.

[19] X. Xie and S. X. Wu, "Earthquake response of bridge restrainers considering failure of bearings," Journal of Zhejiang University, vol. 40, pp. 2180-2185, 2009.

[20] Y. Huang, J. J. Wang, and P. Han, "Seismic response analysis of continuous bridges taking account of bearing failure," China Civil Engineering Journal, vol. 43, pp. 217-223, 2009.

[21] Ministry of Transport of People Republic of China, Series of Elastomeric Pad Bearings for Highway Bridges (JT/T 663-2006), China Communications Press, Beijing, China, 2007. 

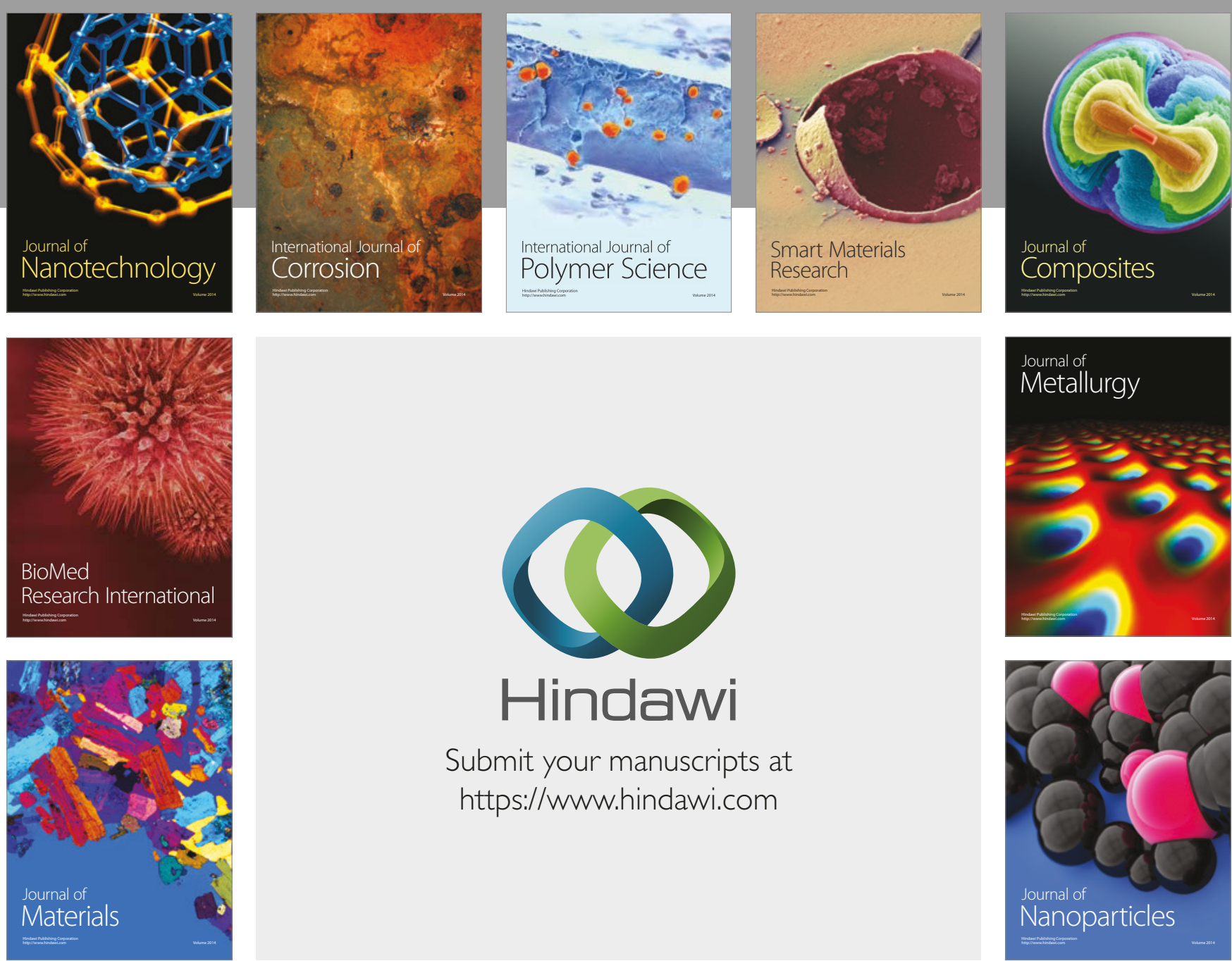

\section{Hindawi}

Submit your manuscripts at

https://www.hindawi.com
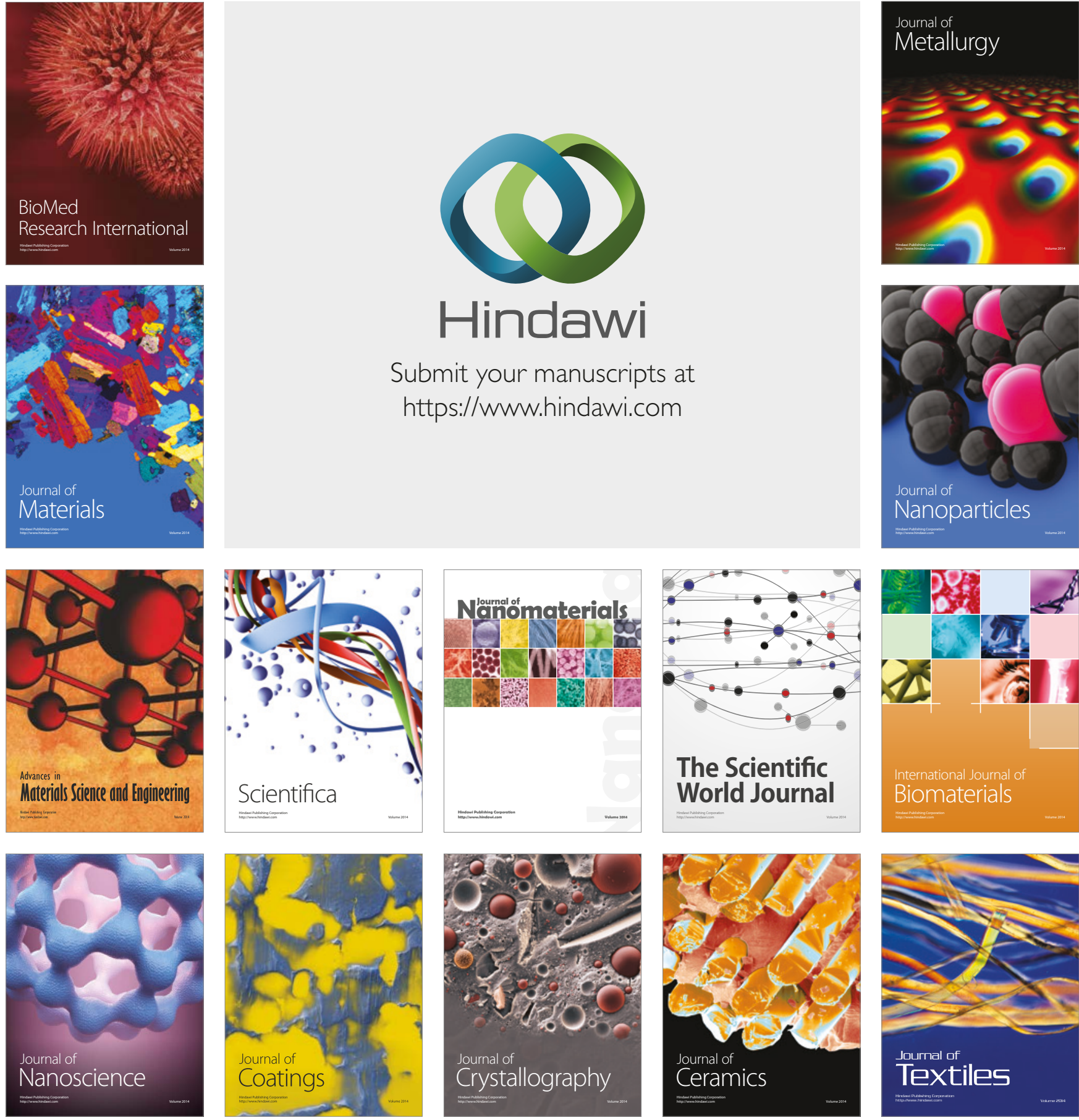

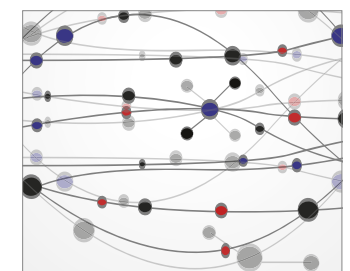

The Scientific World Journal
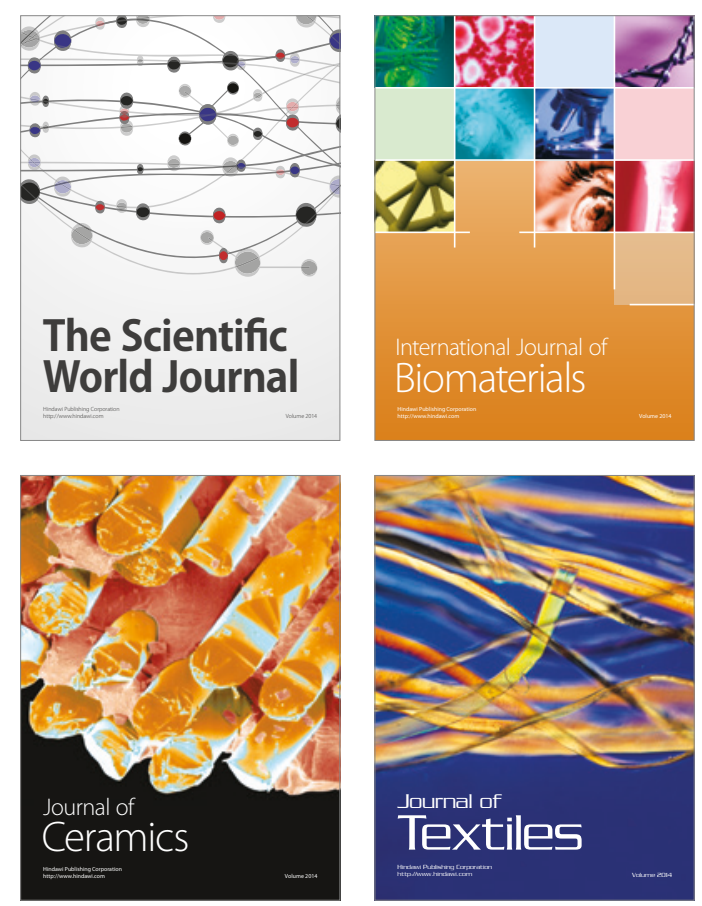